\title{
Visual Cues Are Relevant in Behavioral Control Measures for Cosmopolites sordidus (Coleoptera: Curculionidae)
}

\section{Authors: Gadi V.P. Reddy \& A. Raman}

This is a pre-copyedited, author-produced PDF of an article accepted for publication of Economic. Entomology following peer review. The version of record, as cited below is

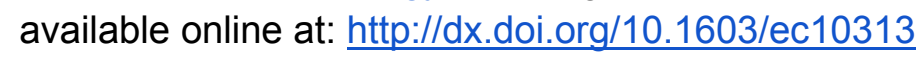

Reddy, G.V.P., and A. Raman. 2011. Visual cues are relevant in behavioral control measures for Cosmopolites sordidus (Coleoptera: Curculionidae). Journal of Economic Entomology 104: 436-442. doi: 10.1603/ec10313

Made available through Montana State University's $\underline{\text { ScholarWorks }}$ scholarworks. montana.edu 


\title{
Visual Cues Are Relevant in Behavioral Control Measures for Cosmopolites sordidus (Coleoptera: Curculionidae)
}

\author{
Gadi V.P. Reddy ${ }^{1}$ and A. Raman ${ }^{2}$ \\ ${ }^{1}$ Corresponding author: Western Pacific Tropical Research Center, \\ College of Natural and Applied Sciences, University of Guam, Mangi- \\ lao, GU 96923 (e-mail: reddy@uguam.uog.edu). \\ ${ }^{2}$ Charles Sturt University and E H Graham Centre for Agricultural \\ Innovation, Orange, NSW 2800, Australia.
}

\begin{abstract}
Trap designs for banana root borer, Cosmopolites sordidus (Germar) (Coleoptera: Curculionidae), have been done essentially on the understanding that $\mathrm{C}$. sordidus rely primarily on chemical cues. Our present results indicate that these borers also rely on visual cues. Previous studies have demonstrated that among the eight differently colored traps tested in the field, brown traps were the most effective compared with the performances of yellow, red, gray, blue, black, white, and green traps; mahogany-brown was more effective than other shades of brown. In the current study, efficiency of ground traps with different colors was evaluated in the laboratory for the capture of $\mathrm{C}$. sordidius. Response of $\mathrm{C}$. sordidus to pheromone-baited ground traps of several different colors (used either individually or as 1:1 mixtures of two different colors) were compared with the standardized mahogany-brown traps. Traps with mahogany-brown mixed with different colors had no significant effect. In contrast, a laboratory color-choice tests indicated C. sordidus preferred black traps over other color traps, with no specific preferences for different shades of black. Here again, traps with black mixed with other colors (1:1) had no influence on the catches. Therefore, any other color that mixes with mahogany-brown or black does not cause color-specific dilution of attractiveness. By exploiting these results, it may be possible to produce efficacious trapping systems that could be used in a behavioral approach to banana root borer control.
\end{abstract}

The banana root borer, Cosmopolites sordidus (Germar) (Coleoptera: Curculionidae), is a major pest in most banana (Musa L.) -growing regions of the world (Stover and Simmonds 1987, Gold et al. 2001), particularly in those regions where bananas are used either in cooking or in making the dessert (Sikora et al. 1989). In recent times, this borer has turned out to be a serious problem in commercial banana farms of Guam and the nearby Micronesian Islands. The larvae of the banana root borer tunnel in the rhizome, weakening the steadiness of the plant and interfering with nutrient uptake. Relatively little damage is caused by adults feeding on plant tissues (Gold et al. 2001). Borer attack can lead to poor crop establishment, plant loss due to snapping and toppling, lower bunch weights (failure to produce suckers), and short plantation life (Rukazambuga et al. 1998, McIntyre et al. 2002, Gold et al. 2004). Yield losses increase with time and can exceed $50 \%$. The banana root borer's host range is restricted to Musa and Ensete (Musaceae). The total life cycle is from 30 to 40 : egg stage, 5-7 d; larval stages, $15-20 \mathrm{~d}$; and pupal stage, $6-8 \mathrm{~d}$. Adults live up to $4 \mathrm{yr}$, are nocturnally active, and have a fecundity rate of $<2$ eggs per wk (Gold et al. 2001).
The data from our previous trapping studies indicated that a high population level ( $>10$ per wk) was recorded in the northern region of Guam, whereas low $(<5$ weevils per wk) to medium (five to 10 weevils per wk) level populations occurred in the southern parts of the island (Reddy et al. 2008). This weevil can cause a yield loss of up to $100 \%$ when left uncontrolled. Recommendations for the integrated pest management (IPM) of the banana root borer emphasize cultural controls, including the use of clean planting material, pseudostem trapping, and crop sanitation (i.e., destruction of crop residues). Trapping with synthetic pheromones (based on the male aggregation pheromone Sordidin) also has been promoted (Reddy and Guerrero 2010). Although several banana root borer predators are available, and attempts at biological control using predatory beetles throughout the Pacific have been made, most of them have been disappointing (Gold et al. 2001).

Because traps for pestiferous insects are important tools in IPM programs, in the present circumstance, use of pheromone traps presents itself as the best option. Trapping with synthetic pheromones (based on Sordidin) has been in use for monitoring populations of C. sordidus (Alpizar et al. 1999; Reddy et al. 2008, 2009). Pheromone traps are limiting by cost, 


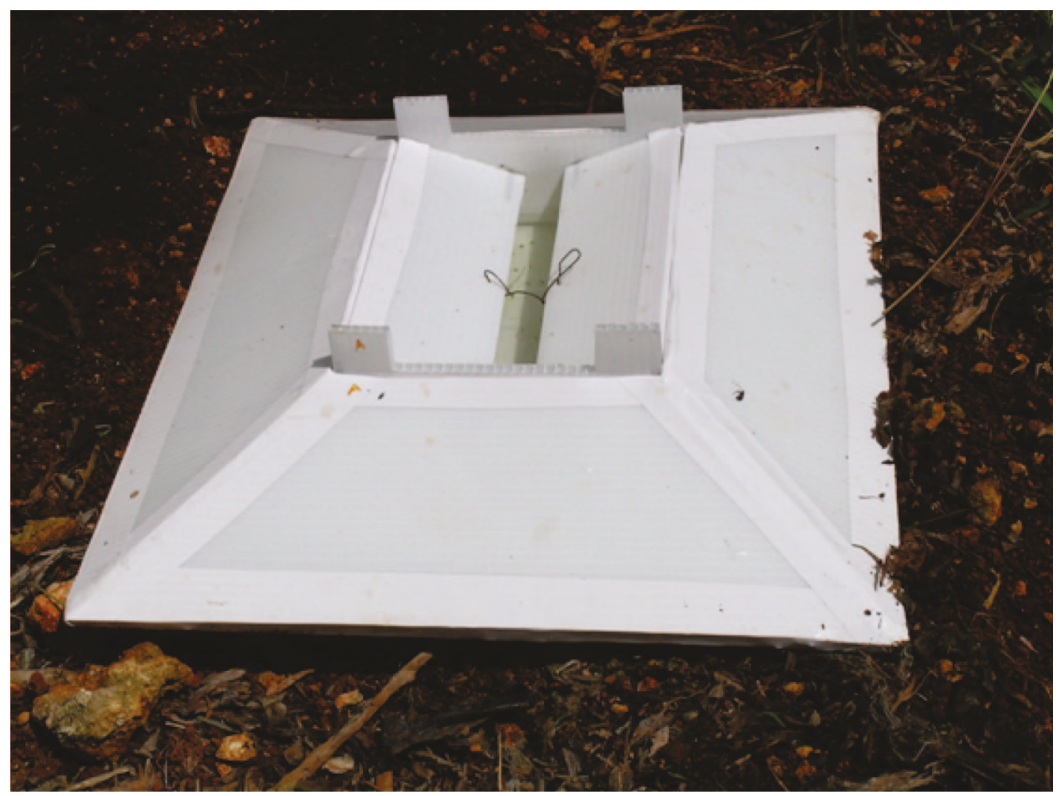

Fig. 1. Ground trap used in the current study.

because use of four pheromone-baited traps per hectare in a single line spaced at $20 \mathrm{~m}$ is vital for efficient management. Moreover, every month the lure has to be replaced and the trap line moved $20 \mathrm{~m}$ such that the entire field is comprehensively covered every $4 \mathrm{mo}$, which renders it labor-intensive.

Scarce data are available on C. sordidus monitoring by using either color or pheromone-embellished color traps. Therefore it became essential to characterize factors that affect trap-capture efficiency to improve trap performance and render traps more reliable in IPM tactics. However, it also may depend upon the accurate representation of borer threat and precision. Adults of C. sordidus use visual and olfactory cues to locate hosts and traps (Reddy et al. 2008, 2009). In previous field experiments, C. sordidus was found to prefer mahogany-brown traps more than the other color traps, indicating that visual cues are critical in mate location (Reddy et al. 2009). The purpose of this study was to determine the effects of trap color in field and indoor environments to develop an efficient semiochemically based trapping method for managing populations of C. sordidus. Here, we report contrasting behavioral responses of $C$. sordidus to differently colored pheromone sources and visual baits in field and laboratory conditions.

\section{Materials and Methods}

Experimental Sites. Field trials were carried out in the island of Guam (United States) at Dededo $\left(13.52^{\circ} \mathrm{N}\right.$, $144.84^{\circ} \mathrm{E}$ ), Mangilao $\left(13.43^{\circ} \mathrm{N}, 144.80^{\circ} \mathrm{E}\right.$ ), Malojloj $\left(13.39^{\circ} \mathrm{N}, 144.45^{\circ} \mathrm{E}\right)$, Inarajan $\left(13.15^{\circ} \mathrm{N}, 144.30^{\circ} \mathrm{E}\right)$, and Yigo $\left(13.54^{\circ} \mathrm{N}, 144.89^{\circ} \mathrm{E}\right)$. The prevailing temperature, relative humidity, and wind velocity were recorded during the trials. Banana plantations (each $\approx 0.8$ ha $[2$ acres] $)$ in these locations were used. Indoor experiments were carried out in the dark laboratory ( 10 by $6 \times 3.5 \mathrm{~m})$ in the Western Pacific Quarantine Biocontrol Laboratory, College of Natural and Applied Sciences at the University of Guam.

As shown in the Fig. 1, the ground trap was constructed in the laboratory using a 40 - by $25-\mathrm{cm}$ white corrugated plastic sheet, with a $25-$ by $12-\mathrm{cm}$ slitted baffle fit at the top to prevent borers from escaping (Reddy et al. 2005). The lower outer edges of the ground traps were shielded in flush with ground to prevent weevils from crawling under the traps. Pheromone (Cosmolure) lures (details in the following paragraph) were suspended from the top of the trap to inside with a wire. Four pheromone-baited traps per ha spaced at $20 \mathrm{~m}$ were used in a single line. Every month, the lure was replaced and the trap line moved $20 \mathrm{~m}$, such that the entire field was systematically covered in 4 mo.

Pheromone Lures. Cosmolure sealed in a white polymer-membrane release device and optimized for C. sordidus (ChemTica Internacional S.A., San José, Costa Rica). The lure packs, each containing $90 \mathrm{mg}$ of pheromone appearing in blue and with a release rate of $3 \mathrm{mg} / \mathrm{d}$ (Tinzaara et al. 2005) were stored at $4^{\circ} \mathrm{C}$ until use. Lures were hung on 2-cm copper wires suspended from the top of each ground trap. The lures were changed usually once (occasionally twice) a month when the transparent container with the pheromone seemed empty. Because C. sordidus occurs on and attacks both indoor and outdoor banana plants, trials were carried out in the field and in the laboratory.

Trap-Color Measurements. Trap-color characteristics were determined using a Konica Minolta CR-410 chromometer (Minolta Instrument Systems, Ramsey, 
Table 1. Color measurements of paint colors mixed with mahogany-brown (m-brown; $1: 1)$ used on ground traps

\begin{tabular}{lcrrr}
\hline \hline \multicolumn{1}{c}{ Trap color } & $\mathrm{L}^{* a}$ & $\mathrm{a}^{* a}$ & $\mathrm{~b}^{* a}$ & Chroma $(\mathrm{C})$ \\
\hline Black/m-brown & $33.30 \pm 0.19$ & $-0.34 \pm 0.01$ & $1.09 \pm 0.03$ & $1.14 \pm 0.02$ \\
Gray/m-brown & $53.01 \pm 0.02$ & $8.59 \pm 0.20$ & $5.44 \pm 0.06$ & $10.16 \pm 0.20$ \\
Yellow/m-brown & $45.90 \pm 0.46$ & $4.17 \pm 0.34$ & $19.81 \pm 0.26$ & $20.25 \pm 0.32$ \\
Red/m-brown & $39.11 \pm 0.11$ & $22.40 \pm 0.25$ & $11.19 \pm 0.07$ & $25.04 \pm 0.25$ \\
White/m-brown & $67.07 \pm 0.07$ & $10.22 \pm 0.02$ & $5.95 \pm 0.03$ & $11.83 \pm 0.03$ \\
Green/m-brown & $36.23 \pm 2.69$ & $-7.12 \pm 0.05$ & $4.83 \pm 0.04$ & $8.61 \pm 0.06$ \\
Blue/m-brown & $34.11 \pm 0.06$ & $-1.09 \pm 0.03$ & $-1.45 \pm 0.01$ & $1.81 \pm 0.01$ \\
\hline
\end{tabular}

Means \pm SD were generated from three observations.

${ }^{a} \mathrm{~L}^{*}, \mathrm{a}^{*}$, and $\mathrm{b}^{*}$ are explained under Trap-Color Measurements.

$\mathrm{NJ})$. L* indicates a measure of "lightness" that runs through the median of the color-scale chart, where 100 (at the top) represents white and 0 (at the bottom) represents black. The a* axis, which runs from left to right on the color chart, indicates a red shade when $>0$ (positive) and a green shade when $<0$ (negative). Similarly, the $b^{*}$ axis which runs vertically through the color chart indicates a yellow shade when positive and a blue shade when negative (Wrolstad et al. 2005).

To measure the influence of trap color on the capture efficiency of C. sordidus, both field and laboratory experiments were carried out. Eight commercially available colors (BEHR Process Corporation, Santa Ana, CA) were procured locally from Home Depot. The 40 - by $25-\mathrm{cm}$ ground trap was used in experiments because this trap size has been shown to have a significant effect in capturing C. sordidus populations in a previous study (Reddy et al. 2009). The ground traps were painted blue (Sailboat: S-H-590), yellow (Sunny Summer: S-G-380), gray (Beluga: $770 \mathrm{~F}-7$ ), green (Pine Grove: 460B-7), brown (Bear Rug: S-G790 ), red (100\% Red: 2-8610), white (Ultra-Pure White: 2-9-850), and black (100\% Black: 2-8620). For the mixed colored traps, two paint colors were blended together and then painted on as single source of the color to the surface of the corrugated plastic.

Influence of Different Colors Mixed With Mahogany-Brown on Trap Catches in Field. Because the mahogany-brown traps caught significantly higher catches than other traps in the field shown in a previous study (Reddy et al. 2009), the ground traps were painted mahogany-brown mixing independently with different colors (1:1). This experiment was conducted to find whether any other color that mixes with mahogany-brown would have any influence on trap catches. The following combinations were used: black/mahogany-brown, gray/mahogany-brown, yellow/mahogany-brown, red/mahogany-brown, white/ mahogany-brown, green/mahogany-brown, and blue/ mahogany-brown. Mahogany-brown (100\%) traps were used as control. Trap-color measurement values $\left(\mathrm{L}^{*}, \mathrm{a}^{*}\right.$, $\mathrm{b}^{*}$, chroma, and hue angle) of these single source colors are supplied in Table 1. Field tests were carried out independently (each color replicated four times at each site) at locations of Dededo, Mangilao, Malojloj, Inarajan, and Yigo. The experiment was carried out from January to April 2009. Trap captures were recorded weekly. The average temperature, relative humidity, and wind velocity during the experimental periods were $30.3-33.2^{\circ} \mathrm{C}, 65-80 \%$, and $0.8-5.3 \mathrm{~m} / \mathrm{s}$, respectively.

Effect of Trap Color on Trap Catches Under Indoor Conditions. Although banana is grown mostly outside, a few commercial farms grow banana under indoor conditions. Because C. sordidus attacks plants both indoors and outdoors, we carried out laboratory experiments to ascertain the behavior of C. sordidus to pheromone-baited traps. To assess the effect of trap color on the capture efficiency of C. sordidus indoors, the experiment was conducted in a 10 - by 6 - by $3.5-\mathrm{m}$ dark laboratory. Because C. sordidus adults are nocturnal (Gold et al. 2001), the field-collected adults were fed with banana rhizome and reared in reversed photoperiod conditions in the insect rearing laboratory ( 8 by 6 by $7 \mathrm{~m}$ ) to facilitate experiments during daytime. The tests were run in the dark laboratory between 1200 and 1730 hours with ground traps of different colors, baited with pheromone lures. Brown, black, gray, yellow, red, white, green, and blue traps were tested independently, with four replicates per color. Trap-color measurement values $\left(\mathrm{L}^{*}, \mathrm{a}^{*}, \mathrm{~b}^{*}\right.$, chroma, and hue angle) of these colors are supplied in Table 2. The traps were placed on the floor of the dark laboratory $2 \mathrm{~h}$ before the release of adults, which allowed the pheromone vapors to diffuse throughout the confines of the laboratory. Air diffused with the sex pheromone was ventilated with an exhaust fan in the laboratory during the experiment. Forty adults were released in the laboratory, but beyond the traps from a distance of $3 \mathrm{~m}$. The number of adults trapped over 3 -h intervals was recorded. Trapped beetles were removed from the trap after capture and discarded. Freshly collected adults were used in the replicate experiments to avoid pseudoreplication. In total, four replicates were conducted for each color trap. The experiment was carried out in May-August 2009. The average temperature, relative humidity, and wind velocity prevailing during the experimental periods in a laboratory experiments were $27.0-27.5^{\circ} \mathrm{C}, 65-70 \%$, and $2.3 \mathrm{~m} / \mathrm{s}$, respectively.

Influence of Different Colors Mixed With Black on Trap Catches Under Indoor Conditions. Because the black traps caught significantly higher catches than other colored traps indoors, the ground traps were painted with black mixing independently (1:1) with different colors to test whether traps with different combinations made with black had any influence on 
Table 2. Color measurements of traps used in the present study

\begin{tabular}{|c|c|c|c|c|c|}
\hline Trap color & $\mathrm{L}^{* a}$ & $\mathrm{a}^{* a}$ & $\mathrm{~b} * a$ & Chroma (C) & Hue angle $\left(h^{\circ}\right)$ \\
\hline Black & $30.44 \pm 0.06$ & $0.42 \pm 0.03$ & $-1.08 \pm 0.04$ & $1.16 \pm 0.05$ & \\
\hline Brown & $35.26 \pm 0.18$ & $3.98 \pm 0.03$ & $3.94 \pm 0.02$ & $5.60 \pm 0.03$ & $44.66 \pm 0.11$ \\
\hline Gray & $39.83 \pm 0.11$ & $-0.17 \pm 0.02$ & $-2.23 \pm 0.01$ & $2.24 \pm 0.01$ & $85.64 \pm 0.47$ \\
\hline Yellow & $82.57 \pm 0.02$ & $-2.92 \pm 0.03$ & $84.02 \pm 0.27$ & $84.07 \pm 0.27$ & $91.99 \pm 0.02$ \\
\hline Red & $42.84 \pm 0.11$ & $49.88 \pm 0.28$ & $19.44 \pm 0.20$ & $53.54 \pm 0.34$ & $21.29 \pm 0.09$ \\
\hline White & $92.29 \pm 0.03$ & $1.34 \pm 0.01$ & $-2.59 \pm 0.04$ & $2.91 \pm 0.03$ & \\
\hline Green & $43.50 \pm 0.08$ & $-27.32 \pm 0.03$ & $1.72 \pm 0.09$ & $27.37 \pm 0.03$ & $176.39 \pm 0.19$ \\
\hline Blue & $36.02 \pm 0.10$ & $15.19 \pm 0.10$ & $-35.82 \pm 0.12$ & $38.91 \pm 0.14$ & $292.98 \pm 0.08$ \\
\hline
\end{tabular}

Means \pm SD were generated from three observations

${ }^{a} \mathrm{~L}^{*}, \mathrm{a}^{*}$, and $\mathrm{b}^{*}$ are explained under Trap-Color Measurements.

the trap catches. The following combinations were used: red/black, white/black, yellow/black, blue/black, gray/black, green/black, brown/black, mixed black, and mixed black (pure black + light black)/black. Black (100\%) traps served as control. Trap-color measurement values ( $\mathrm{L}^{*}, \mathrm{a}^{*}, \mathrm{~b}^{*}$, chroma, and hue angle) of these single source colors are supplied in Table 3. The method of adult release and capture was followed as described above. These tests also were carried out individually (four replicates per color) under the same dark laboratory conditions. Data collected included the numbers of C. sordidus caught in each trap. The experiment was carried out in September-December 2009.

Influence of Different Shades of Black on Trap Catches Under Indoor Conditions. Because black traps caught significantly $(P<0.05)$ more adults than other colored traps in the laboratory, different shades of black (100\% black, mixed black, black medium, black thick) were evaluated. Trap-color measurement values $\left(\mathrm{L}^{*}, \mathrm{a}^{*}, \mathrm{~b}^{*}\right.$, chroma, and hue angle) of these colors are given in Table 4 . A 40- by 25 -cm ground trap was used, and these shades of different black were tested independently (four replicates per color). The method of adult releases and capture was followed as described in a previous experiment. The experiment was conducted January-April 2010.

Statistical Analysis. The data were analyzed using the general linear model procedure of SAS version 9.13 (SAS Institute, Cary, NC). Because all the response variables used in the experiments were count variables, a one-way Poisson analysis of variance (ANOVA) model was fitted using the GLIMMIX procedure. For comparisons of means, the least square means test was applied to make multiple comparisons for significant differences at $P=0.05$ between treatments.

\section{Results}

Effect of Trap Color. The current study indicated that mahogany-brown traps mixed with different colors had no significant $(P=0.05)$ effect in capturing $C$. sordidus under field conditions. Mahogany-brown traps caught significantly higher numbers than the traps with mixed colors $(F=13.12$; $\mathrm{df}=7,88 ; P<$ 0.001) (Fig. 2).

Laboratory trials showed that, black ground traps attracted more of $C$. sordidus adults than any other color $(F=10.16$; $\mathrm{df}=7,88 ; P<0.05)$ (Fig. 3 ). Black traps caught, on average, $13.5 \pm 1.8$ adults per trap, significantly more than those caught with brown traps ( $8.8 \pm 0.7$ adults per trap), the second most preferred trap. A significant difference $(P<0.001)$ between brown and red traps existed, but none among the red, gray, blue, white, yellow, and green traps.

Trap color (black with different colors) measurement values $\left(\mathrm{L}^{*}, \mathrm{a}^{*}, \mathrm{~b}^{*}\right.$, chroma, and hue angle) are provided in Table 3. In the laboratory, black traps mixed with different colors had no significant $(P=$ 0.05 ) effect in capturing $C$. sordidus adults in laboratory trials. Traps with $100 \%$ black, mixed black, and mixed black/black captured significantly greater catches than the traps with other tested colors $(F=$ 11.24; $\mathrm{df}=7,88 ; P<0.001$ ) (Fig. 4).

Table 3. Color measurements of paint colors mixed with pure black (1:1) used on ground traps

\begin{tabular}{|c|c|c|c|c|c|}
\hline Trap color & $\mathrm{L}^{*}$ & $\mathrm{a}^{*}$ & $b^{*}$ & Chroma (C) & Hue angle $\left(\mathrm{h}^{\circ}\right)$ \\
\hline Red/black & $33.80 \pm 0.02$ & $1.75 \pm 0.01$ & $2.45 \pm 0.02$ & $3.01 \pm 0.01$ & $54.42 \pm 0.40$ \\
\hline White/black & $49.21 \pm 0.05$ & $-1.04 \pm 0.01$ & $-1.82 \pm 0.01$ & $2.10 \pm 0.01$ & $60.38 \pm 0.12$ \\
\hline Yellow/black & $34.60 \pm 0.10$ & $-2.61 \pm 0.02$ & $3.19 \pm 0.05$ & $4.12 \pm 0.04$ & \\
\hline Blue/black & $31.67 \pm 0.48$ & $-0.19 \pm 0.02$ & $0.66 \pm 0.03$ & $0.68 \pm 0.02$ & \\
\hline Gray/black & $38.67 \pm 0.12$ & $-0.49 \pm 0.02$ & $-1.02 \pm 0.03$ & $1.13 \pm 0.02$ & $64.48 \pm 1.24$ \\
\hline Green/black & $33.09 \pm 0.13$ & $-0.92 \pm 0.01$ & $0.77 \pm 0.04$ & $1.20 \pm 0.03$ & \\
\hline Mix black/black & $32.48 \pm 0.05$ & $-0.16 \pm 0.02$ & $0.81 \pm 0.04$ & $0.82 \pm 0.04$ & \\
\hline Brown/black & $33.41 \pm 0.14$ & $-0.36 \pm 0.02$ & $1.10 \pm 0.02$ & $1.15 \pm 0.02$ & \\
\hline Pure black & $32.75 \pm 0.24$ & $-0.18 \pm 0.03$ & $0.72 \pm 0.03$ & $0.74 \pm 0.02$ & \\
\hline Mix black & $31.89 \pm 0.03$ & $-0.12 \pm 0.02$ & $0.95 \pm 0.02$ & $0.96 \pm 0.02$ & \\
\hline
\end{tabular}

Means \pm SD were generated from three observations.

${ }^{a} \mathrm{~L}^{*}, \mathrm{a}^{*}$, and $\mathrm{b}^{*}$ are explained under Trap-Color Measurements. 
Table 4. Color measurements of the different shades of black

\begin{tabular}{lccr}
\hline \hline \multicolumn{1}{c}{ Trap color } & L*a & $\mathrm{a}^{* a}$ & $\mathrm{~b}$ \\
\hline Pure black & $32.75 \pm 0.24$ & $-0.18 \pm 0.03$ & $0.72 \pm 0.03$ \\
Mix black & $31.89 \pm 0.03$ & $-0.12 \pm 0.02$ & $0.95 \pm 0.02$ \\
Black medium & $30.44 \pm 0.06$ & $0.42 \pm 0.03$ & $-1.08 \pm 0.04$ \\
Black thick & $33.8 \pm 0.1$ & $7.6 \pm 0.2$ & $-5.4 \pm 0.1$ \\
\hline
\end{tabular}

Means \pm SD were generated from three observations.

${ }^{a} \mathrm{~L}^{*}, \mathrm{a}^{*}$, and $\mathrm{b}^{*}$ are explained under Trap-Color Measurements.

Effect of Different Shades of Black on Trap Catches Under Indoor Conditions. No significant difference occurred in trials made comparing between different black traps (pure black, mixed black, black medium, and black thick) in capturing the $C$. sordidus adults in indoor conditions $(P=0.05$; data not shown).

\section{Discussion}

Insect vision discriminates colors in outdoor and indoor conditions differently (Kelber 1999, Dyer and Chittka 2004). Adults of C. sordidus responded to semiochemically baited ground traps differently under field and indoor conditions. In the field, C. sordidus preferred brown over the other colors; preference for mahogany-brown was significantly higher than other shades (Reddy et al. 2009). On the contrary, C. sordidus was attracted to black traps in the laboratory. Why C. sordidus behavior changes from the field to indoors is unclear. That color influences the efficiency of the pheromone traps has been documented in a previous study (Reddy et al. 2009). We also hypothesize that any other color that mixes with mahoganybrown would dilute the attractiveness of the brown and give a lower catch in the field and that this effect does not seem to be color specific i.e., mixing in gray seems to have a similar dilution effect as mixing in yellow, etc. Similarly, any other color that mixes with

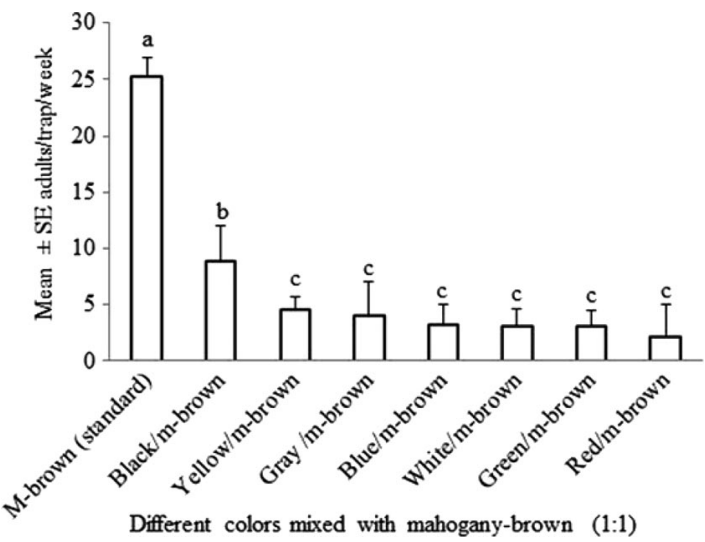

Fig. 2. Mean \pm SE numbers of adult $C$. sordidus caught in pheromone-baited ground traps of different colors mixed with black color (1:1) in a laboratory. Different lowercase letters indicate significant differences between treatments (one-way ANOVA using Poisson model, least square means, $P<0.01)$. Bars represent means of four replicates. black would dilute the attractiveness of the black and give a lesser catch in the laboratory.

Why color is critical for nocturnal insects is an ongoing debate. Nocturnal insect taxa discriminate flowers at starlight intensities, whereas humans and honey bees (Apis mellifera L.) cannot (Kelber et al. 2003). Most of our knowledge on color vision in nocturnal insects remains confined to sphingids and halictids. For example, Macroglossum stellatarum (L.) (Lepidoptera: Sphingidae) uses achromatic, intensityrelated cue if color cues are absent. Even in "dim" starlight, however, nocturnal insects use chromatic cues rather than achromatic cues to recognize flowers (Kelber et al. 2003). The fast-flying nocturnal sweat bee Megalopta genalis Meade-Waldo (Hymenoptera: Halictidae) relies on vision as a principal sense and is capable of foraging and homing by using visually discriminated landmarks at starlight intensities (Warrant et al. 2004, Frederiksen et al. 2008). Our results show that trap color influenced the capture efficiency of $C$. sordidus.

Pheromone-based trapping is a valuable and an ecofriendly management tactic for many insects, particularly the embedded insects (e.g., endophagous insects), where insecticide application is neither feasible nor relevant (Reddy and Guerrero 2004, 2010). Use of visual cues is well documented in predatory Coleoptera. For example, the larvae of a tiger beetle, Cicindela chinensis De Geer, visually discriminate prey within their hunting range of $10-15 \mathrm{~mm}$ (Mizutani and Toh 1998, Toh and Okamura 2001), whereas such a capability has not been demonstrated in plant-feeding Coleoptera. Many examples illustrat-

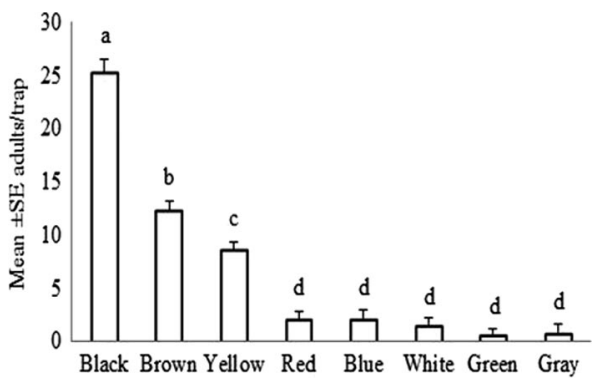

Fig. 3. Mean $\pm \mathrm{SE}$ numbers of adult $C$. sordidus caught in pheromone-baited ground traps of different colors in a laboratory. Different lowercase letters indicate significant differences between treatments (one-way ANOVA using Poisson model, least square means, $P<0.001$ ). The means were generated from eight tests each using 30 insects. 


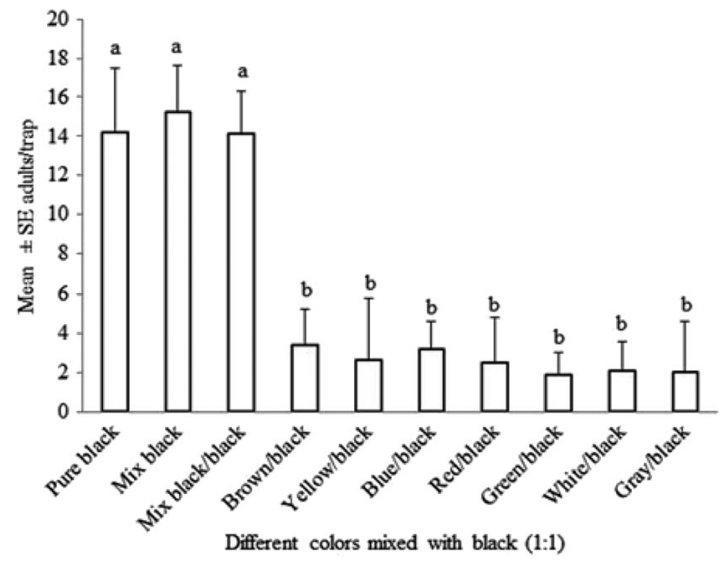

Fig. 4. Mean \pm SE numbers of adult $C$. sordidus caught in pheromone-baited ground traps of different colors mixed with mahogany-brown (m-brown) per (1:1) in the field. Different lowercase letters indicate significant differences between treatments (one-way ANOVA using Poisson model, least square means, $P<0.01)$. Bars represent means of four replicates.

ing use of visual cues in mate location exist (Fukaya et al. 2004), but they do not explain that visual cues work in coordination with olfactory cues. However, verifying the recognition capabilities of the monophagous Altica engstroemi (Sahlberg) (Coleoptera: Chrysomelidae), Stenberg and Ericson (2007) have categorically demonstrated the greater vitality and relevance of visual cues than olfactory cues. They have suggested that the use of visual cues in host finding may have evolved among the docile chrysomelids in persistent habitats; they have argued that monophagous chrysomelids use visual cues in contexts where host plants occur plentifully, reinforcing the criticality of Feeny's apparency theory (Feeny 1976). Numerous examples indicating that visual cues are important for other docile species are available (Prokopy and Owens 1983, Blackmer and Cañas 2005).

Results from the current study indicate that color cues work synchronously with the olfactory cues and such a coordinated function can be usefully explored in insect trapping for either controlling or monitoring their abundance in either field or indoor conditions. In the current study, the best traps (mahogany-brown ground traps) caught on an average of 25 beetles per wk in the field, whereas identical black traps captured, on average, 25 adults indoors. This indicates that control could be effective when considering the reproductive capacity of those trapped beetles, and the number of traps that could potentially be placed in the field or under indoor conditions. Moreover, what is clearer is that behavioral traits seem to vary among different insect taxa. For example, docile beetles show a different behavioral trait to those that are active. Similar variations, but in greater amplitude, occur in insects of different groups such as Hymenoptera and Coleoptera (Menzel and Backhaus 1991, Kelber 2006).

\section{Acknowledgments}

We thank R. Gumataotao for help with fieldwork. We thank Bernie Roitberg and an anonymous reviewer for valuable comments. This project was supported by Professional Development Program of the USDA-Western SARE Project 2009-EW09-012/Utah State University subaward 090757010; Western Integrated Pest Management Center award 200751120-03885/University of California, Davis, subaward 07001492-GUAM3; and Hatch funds (project GUA0561).

\section{References Cited}

Alpizar D, M. Fallas, A. C. Oehlschlager, L. Gonzalez, and S. Jayaraman. 1999. Pheromone-based mass trapping of the banana weevil, Cosmopolites sordidus (German) and the West Indian sugarcane weevil Metamasius hemipterus L. (Coleoptera: Curculionidae) in plantain and banana, pp. 515-538. In Memorias XIII Reunion ACORBAT, 23-27 November 1998, Guayaquil, Ecuador.

Blackmer, J. L., and L. A. Cañas. 2005. Visual cues enhance the response of Lygus hesperus (Heteroptera: Miridae) to volatiles from host plants. Environ. Entomol. 34: 15241533.

Dyer, A. G., and L. Chittka. 2004. Fine colour discrimination requires differential conditioning in bumblebees. Naturwissenschaften 91: 224-227.

Feeny, P. 1976. Plant apparency and chemical defense. Recent Adv. Phytochem. 10: 1-40.

Frederiksen, R., W. T. Wcislo, and E. J. Warrant. 2008. Visual reliability and information rate in the retina of a nocturnal bee. Curr. Biol. 18: 349-353.

Fukaya, M., N. Arakaki, H. Yasui, and S. Wakamura. 2004. Effect of colour on male orientation to female pheromone in the black chafer Holotrichia loochooana loochooana. Chemoecology 14: 225-228.

Gold, C. S., E. G. Karamura, and J. E. Peña. 2001. Biology and integrated pest management for the banana weevil Cosmopolites sordidus (Germar) (Coleoptera: Curculionidae). Integr. Pest Manage. Rev. 6: 79-155.

Gold, C. S., G. H. Kagezi, G. Night, and P. E. Ragama. 2004. The effects of banana weevil, Cosmopolites sordidus (Germar), damage on highland banana growth, yield and stand duration in Uganda. Ann. Appl. Biol. 145: 263-269.

Kelber, A. 1999. Ovipositing butterflies use a red receptor to see green. J. Exp. Biol. 202: 2619-2630.

Kelber, A. 2006. Invertebrate colour vision, pp. 250-290. In E. J. Warrant and D.-E. Nilsson [eds.], Invertebrate vision. Cambridge University Press, Cambridge, United Kingdom.

Kelber, A., A. Balkenius, and E. J. Warrant. 2003. Color vision in diurnal and nocturnal hawkmoths. Integr. Comp. Biol. 43: 571-579.

McIntyre, B. D., C. S. Gold, I. N. Kashaija, H. Ssali, G. Night, and D. P. Bwamiki. 2002. Effects of legume intercrops on soil-borne pests, biomass, nutrients and soil water in banana. Biol. Fertil. Soils 39: 74-79.

Menzel, R., and W. Backhaus. 1991. Colour vision in insects, pp. 262-293. In P. Gouras [ed.], Vision and visual dysfunction, vol. 6. The perception of colour. Macmillan Press, London, United Kingdom.

Mizutani, A., and Y. Toh. 1998. Behavioral analysis of two distinct visual responses on the larva of the tiger beetle (Cicindela chinensis). J. Comp. Physiol. A 182: 277-286.

Prokopy, R. J., and E. O. Owens. 1983. Visual detection of plants by herbivorous insects. Annu. Rev. Entomol. 28: 337-364 
Reddy, G.V.P., R. Fettköther, U. Noldt, and K. Dettner. 2005. Capture of female Hylotrupes bajulus as influenced by trap type and pheromone blend. J. Chem. Ecol. 31: 21692177.

Reddy, G.V.P., and A. Guerrero. 2004. Interactions of insect pheromones and plant semiochemicals. Trends Plant Sci. 9: 253-261.

Reddy, G.V.P., and A. Guerrero. 2010. New pheromones and insect control strategies. Vitam. Horm. 83: 493-519.

Reddy, G.V.P., Z. T. Cruz, and A. Guerrero. 2009. Development of an efficient pheromone-based trapping method for the banana root borer Cosmopolites sordidus. J. Chem. Ecol. 35: 111-117.

Reddy, G.V.P., Z. T. Cruz, F. Naz, and R. Muniappan. 2008. A pheromone-based trapping system for monitoring the population of Cosmopolites sordidus (Germar) (Coleoptera: Curculionidae). J. Plant Prot. Res. 48: 515-527.

Rukazambuga, N.D.T.M., C. S. Gold, and S. R. Gowen. 1998. Yield loss in East African highland banana (Musa spp., AAA-EA group) caused by the banana weevil, Cosmopolites sordidus Germar. Crop Prot. 17: 581-589.

Sikora, R. A., N. D. Bafokuzara, A.S.S. Mbwana, G. W. Oloo, B. Uronu, and K. V. Seshu Reddy. 1989. Interrelationship between banana weevil, root lesion nematode and agronomic practices and their importance for banana decline in the United Republic of Tanzania. FAO Plant Prot. Bull. 37: 151-157.
Stenberg, J. A., and L. Ericson. 2007. Visual cues override olfactory cues in the host-finding process of the monophagous leaf beetle Altica engstroemi. Entomol. Exp. Appl. 125: 81-88.

Stover, R. H., and N. W. Simmonds. 1987. Bananas. Tropical Agricultural Series. Longman Scientific and Technical, Essex, United Kingdom.

Tinzaara, W., C. S. Gold, G. H. Kagezi, M. Dicke, A. van Huis, C. M. Nankinga, W. Tushemereirwe, and P. E. Rragama. 2005. Effects of two pheromone trap densities against banana weevil, Cosmopolites sordidus, populations and their impact on plant damage in Uganda. J. Appl. Entomol. 129: 265-271.

Toh, Y., and J. Y. Okamura. 2001. Behavioural responses of the tiger beetle larva to moving objects: role of binocular and monocular vision. J. Exp. Biol. 204: 615-625.

Warrant, E. J., A. Kelber, A. Gislén, B. Greiner, W. A. Ribi, and W. T. Wcislo. 2004. Nocturnal vision and landmark orientation in a tropical halictid bee. Curr. Biol. 14: 13091318

Wrolstad, R. E., R. W. Durst, and J. Lee. 2005. Tracking color and pigment changes in anthocyanin products. Trends Food Sci. Technol. 16: 423-428. 